\title{
Speed Control System of the Generator with the Radial Magnetic Coupling Using Second Order Model
}

\author{
Soontorn Odngam and Jiraphon Srisertpol ${ }^{*}$ \\ System and Control Engineering Lab, School of Mechanical Engineering, Suranaree University of Technology, Thailand \\ ${ }^{*}$ Corresponding author
}

\begin{abstract}
The Radial Magnetic Coupling (RMC) is the connected device of the automatic transmission by controlling the power of magnetic coil in order to adjust round speed as needed. The Radial Magnetic Coupling system is non-linear model that make it difficult to design the control system. This paper proposed a sample design for the speed control of the generator with the RMC using second order model. The speed control system with the PI Controller can maintain the speed of the generator that has disturbance such as variable speed outer rotor and load efficiency.
\end{abstract}

Keywords-radial magnetic coupling; second order model; system identification; PI controller

\section{INTRODUCTION}

The generator's performance should be controlled speed and torque of the rotor. The wind turbine generator used the transmission system to control the speed and torque of the generator. To optimize the power of the wind turbine generator, it must be able to with the wind speed [1]. in order to improve the radial magnetic coupling (RMC) and reduce parasitic loss of transmission or application for industries. Yao et al [2] studied the torque, material, distance of the magnetic coupling between radial magnetic gears. Montague, Bingham and Atallah considered the analysis and application of magnetic gearbox and magnetic coupling technologies and issues surrounding their use of the motion control servo systems [3-4]. The advantage of electromagnetic clutch water pump in vehicle engine cooling system can be reduced fuel consumption [5]. Chakravarthi et al [6] are designed a robust PI controller for a second order system plus delay (SOSPD) which has an inherent nonlinearity by the virtue of its structural dynamics. Yoo, Kwak and Lee proposed an identification method to estimate the second order time delay (SOPTD) model parameters. The proposed method directly obtains these parameters using a frequency-weighted integral transform and a least-squares method [7]. Pongamg et al [8] investigated the mathematical model via system identification and optimized controller for reheating furnace walking hearth type.

This paper develops simple speed control system of the generator with the RMC using second order model. PI controller design is applied by using Signal-Constraints of MATLAB/Simulink program. The experimental and simulation results can be effective on controlled speed of the generator in 600-800 rpm range. The case studies are considered disturbances such as speed outer rotor in 2000 $3000 \mathrm{rpm}$ range and load.

\section{CONTROL SyStem DESIGN}

\section{A. Control System Diagram}

The control system diagram is considered the speed control of the generator such as wind turbine generator. The inner rotor is connected to the generator and outer rotor is connected to motor with closed-loop speed control acting as variable wing speed turbine. The RMC is used to coupling and decoupling between outer and inner rotor functioning as transmission system in wind turbine generator. This research demonstrates speed control system diagram of the generator with the RMC as shown in Fig I. The one side of the generator is connected to the inner rotor of the RMC. The objective of the control system must be constant speed control of the generator $\left(\omega_{\text {out }}\right)$ with the RMC. The $G(s)$ is the second order model according to the RMC. The PI-controller has a transfer function $G_{c}(s)$ as

$$
G_{c}(s)=K_{p}+\frac{K_{i}}{s}
$$

Where $K_{p}$ is the controller is proportional gain, ${ }^{i}$ is the integral controller

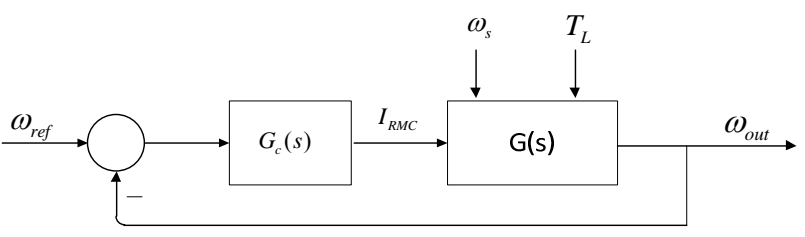

FIGURE I. CONTROL SYSTEM DIAGRAM OF THE RMC

where, $\omega_{\text {ref }}$ is the speed of inner rotor reference of the generator, $\omega_{s}$ is the speed of outer rotor from motor, $\omega_{\text {out }}$ is the speed of inner rotor of the generator, $I_{R M C}$ is the current of the RMC and $T_{L}$ is the load of the generator. 


\section{B. Mathematical Modeling of the RMC}

The radial magnetic coupling (RMC) is consisted of outer rotor and inner rotor, as shown in Figure II. The outer rotor is made of steel material that attaches to the shaft of the prime motor power as an input $\left(\omega_{s}\right)$ to the inner rotor. To excite coil in inner rotor, it generates excited magnetic field. Main parameters of the RMC are shown in Table I.

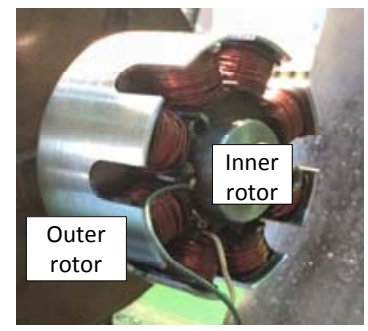

FIGURE II. RADIAL MAGNETIC COUPLING

TABLE I. PARAMETERS OF THE RMC

\begin{tabular}{|c|c|c|}
\hline Parameter & value & unit \\
\hline Outer rotor outside diameter & 100 & $\mathrm{~mm}$ \\
\hline Inner rotor outside diameter & 96 & $\mathrm{~mm}$ \\
\hline Inner rotor coil resistance & 2 & $\Omega$ \\
\hline Pole of inner rotor & 8 & pole \\
\hline
\end{tabular}

The nature of the radial magnetic coupling (RMC) is complex system and non-linear model. The dynamics of this system can be described by the second order equation via linearization technique. The transfer function between input $\left(I_{R M C}\right)$ and output $\left(\omega_{\text {out }}\right)$ can be obtained

$$
G(s)=\frac{K \omega_{n}^{2}}{s^{2}+2 \zeta \omega_{n} s+\omega_{n}^{2}}
$$

where $K$ is the static gain, $\omega_{n}$ is the natural frequency and $\zeta$ is the damping ratio.

\section{EXPERIMENTAL AND SIMULATION RESULTS}

This section consists of the experimental setup and dynamic responses of the control system.

\section{A. Experimental Setup}

Figure III shows experimental setup of the speed control system of the generator with the RMC. The inner rotor part of the RMC consists magnetic coil of 8 poles. The current of the RMC ranges from $0-16$ amp at 12 voltage. The magnetic field creates an attraction to the inner and outer rotors in order to rotate together. The speed outer rotor $\left(\omega_{s}\right)$ of the RMC is controlled by closed-loop PI controller. The generator with the RMC includes the generator, speed sensor, DC motor and microcontroller interface to computer. The signals linked to computer and board which is an electronic board functioning as a device linking between computers with the experimental equipment through serial cable to PCI serial card of computers.

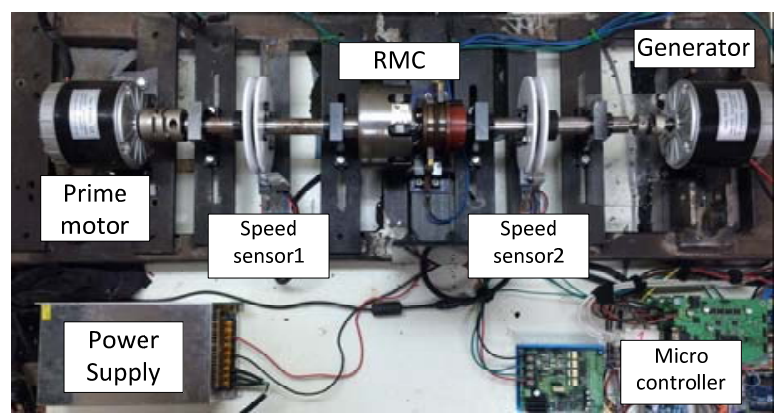

FIGURE III. EXPERIMENTAL SETUP

\section{B. System Identification of Second Order Model}

First of all, the relationship between input and output responses in range of linear model must be investigated. The speed outer rotor $\left(\omega_{s}\right)$ has $2000-3000 \mathrm{rpm}$ range which is related to the speed inner rotor's $600-800 \mathrm{rpm}$ range. The mathematical model of the generator with the RMC can be estimated by measuring speed inner rotor $\left(\omega_{\text {out }}\right)$ and current of the RMC ( $\left.I_{R M C}\right)$ using Parameter Estimation of MATLAB/Simulink program. The parameters of the model is shown in Table II.

TABLE II. PARAMETERS OF SECOND ORDER MODEL

\begin{tabular}{|c|c|c|c|}
\hline \multirow{2}{*}{} & \multicolumn{3}{|c|}{ Parameter } \\
\cline { 2 - 4 } & $K$ & $\zeta$ & $\omega_{n}$ \\
\hline value & 21.6628 & 1.1829 & 1.2133 \\
\hline
\end{tabular}

The speed responses of the generator with the RMC are compared between the model and experiment as shown in Fig. IV. The result revealed that the parameter estimation of the second order model and speed inner rotor was accorded in 600-800 rpm range.

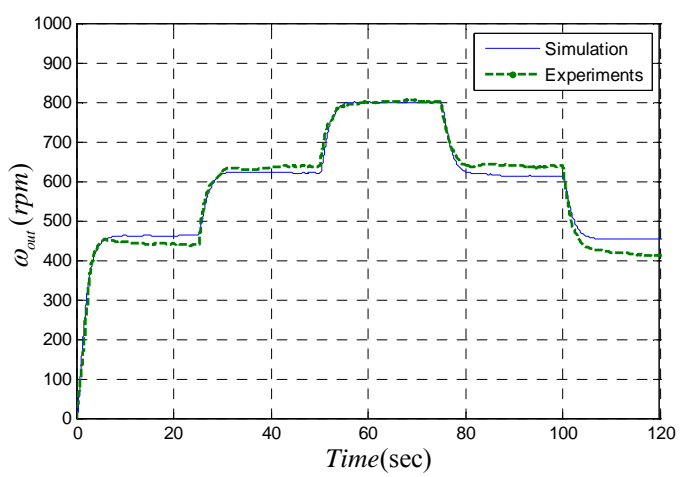

FIGURE IV. SPEED RESPONSES OF THE GENERATOR WITH THE RMC 


\section{Optimaization PI Contoller}

The parameters of PI controller can be determined by using Signal-constraints of MATLAB/Simulink program. Parameter and functional constraints limits the maximum overshoot $20 \%$, Rise time $<0.2 \mathrm{sec}$ and Setting time $<7.5 \mathrm{sec}$. The result of this program defined is shown in Table III.

TABLE III. PARAMETERS OF PI CONTROLLER

\begin{tabular}{|c|c|c|}
\hline \multirow{2}{*}{ value } & \multicolumn{2}{|c|}{ Parameter } \\
\cline { 2 - 3 } & $\boldsymbol{K}_{\boldsymbol{p}}$ & $\boldsymbol{K}_{\boldsymbol{i}}$ \\
\hline & 0.2806 & 0.0792 \\
\hline
\end{tabular}

\section{Experiment Results}

The speed control of the generator with the RMC can be examined by an experimental design. The experiments have three cases with regard to variable input reference and perturbing system.

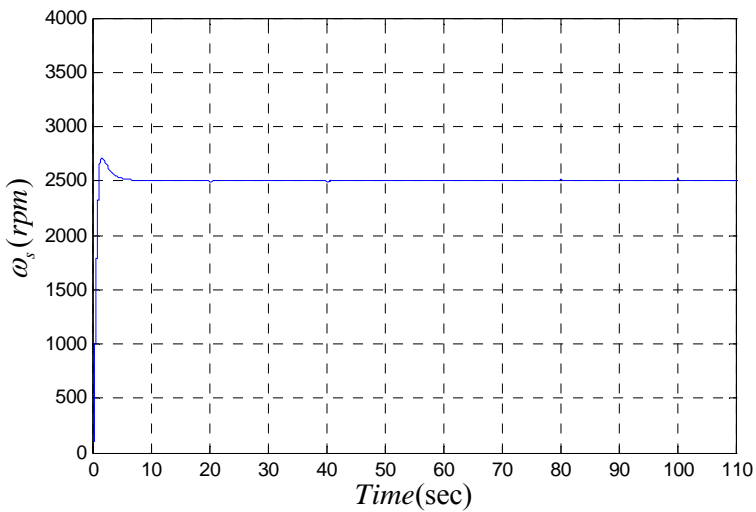

FIGURE V. SPEED OUTER ROTOR RESPONSE

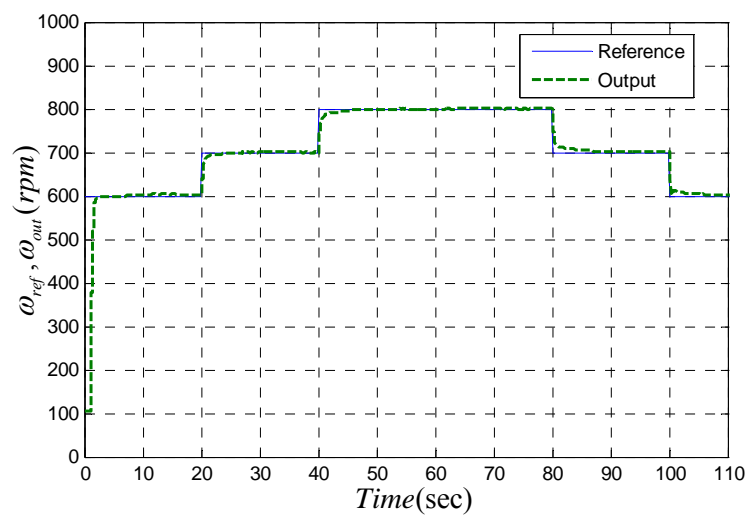

FIGURE VI. SPEED INNER ROTOR RESPONSES WITH STEP INPUT

First case of an experiment insists to variable step input $\left(\omega_{\text {ref }}\right)$ with constant speed outer rotor $\left(\omega_{s}\right)$ as shown in Figure $\mathrm{V}$ and Figure VI. The current profile $\left(I_{R M C}\right)$ depends on the PI controller to step input as shown in Figure VII. The step input changes in range from $600-800 \mathrm{rpm}$ and speed inner rotor response ( $\omega_{\text {out }}$ ) accords to variable step input.

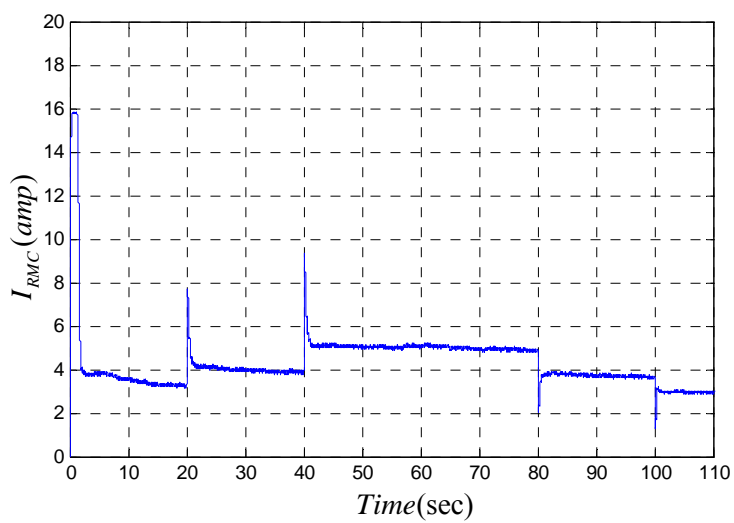

FIGURE VII. CURRENT PROFILE OF THE RMC



FIGURE VIII. HARMONIC SPEED OUTER ROTOR

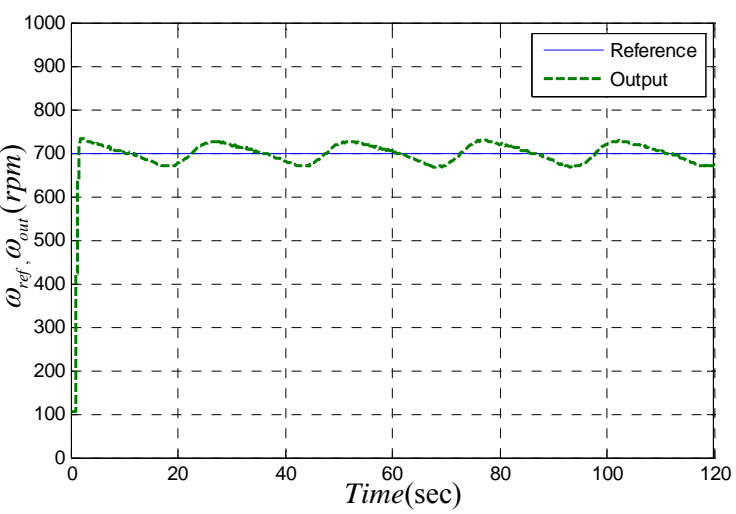

FIGURE IX. SPEED INNER ROTOR RESPONSES

Second case, the speed outer rotor $\left(\omega_{\mathrm{s}}\right)$ is the harmonic $\omega_{s}(t)=2500-500 \cos \omega t \mathrm{rpm}$ and $\omega=0.25 \mathrm{rad} / \mathrm{sec}$ as shown in Figure VIII. The speed inner rotor reference $\left(\omega_{\text {ref }}\right)$ is constant speed at $700 \mathrm{rpm}$ and the current profile is shown in Figure $X$. The speed inner rotor $\left(\omega_{\text {out }}\right)$ control responses can 
efficiently maintain speed with disturbance such as harmonic outer rotor as shown in Figure IX.

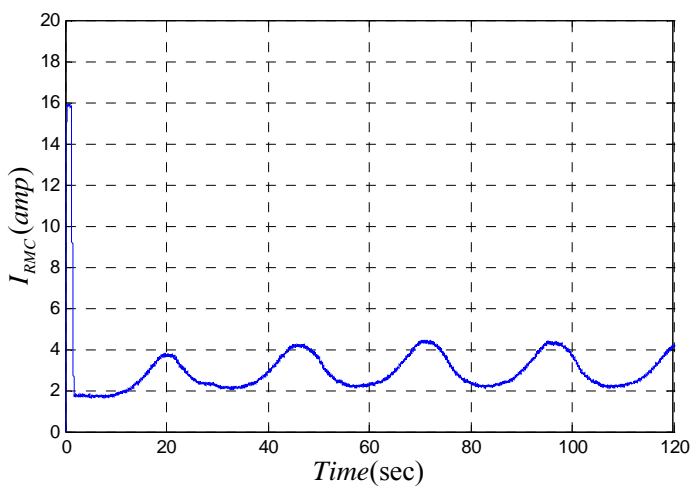

FIGURE X. CURRENTS PROFILE OF THE RMC

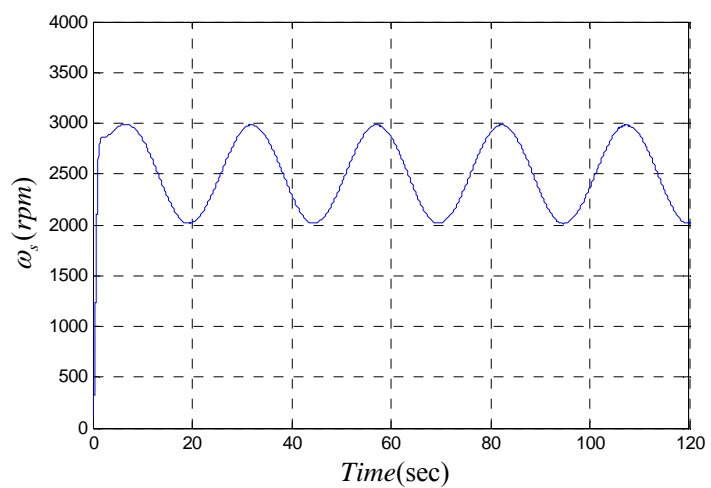

FIGURE XI. HARMONIC SPEED OUTER ROTOR

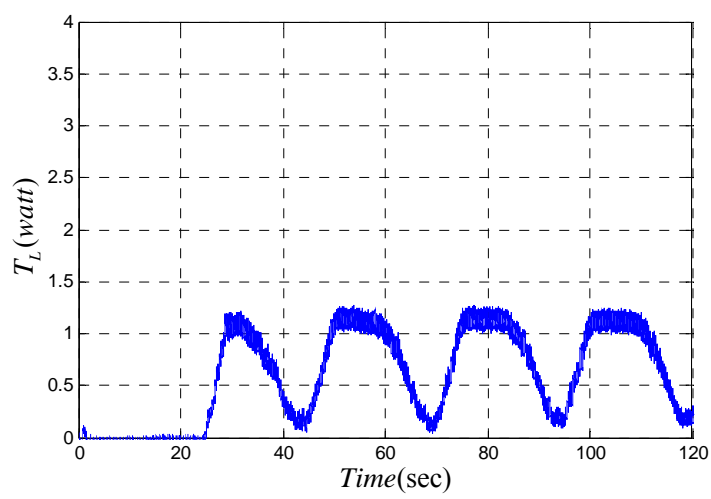

FIGURE XII. LOAD PROFILE

Third case the disturbances are applied to inner rotor speed that variable the outer rotor speed and load from the generator. The speed outer rotor $\left(\omega_{s}\right)$ has a harmonic of $\omega_{s}(t)=2500-500 \cos \omega t \mathrm{rpm}$ and $\omega=0.25 \mathrm{rad} / \mathrm{sec}$ as shown in Figure XI. The load profile $\left(T_{L}\right)$ is shown in Figure XII. Under these conditions, the control of inner rotor speed at 700 rpm can be efficiently maintained with disturbance as shown in Figure XIII. The current control $\left(I_{R M C}\right)$ is the compensated power to the magnetic fieled of the inner rotor with the disturbances acting on the control system as shown in Figure XIV. Examining the resulting response, the inner rotor's speed seems to settle out near the reference of $700 \mathrm{rpm}$.

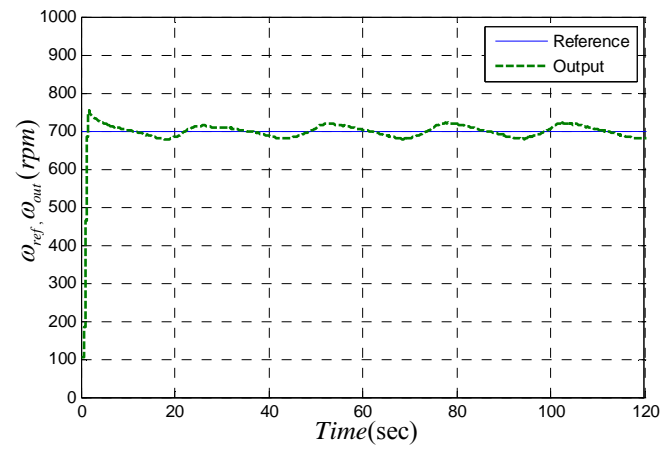

FIGURE XIII. SPEED INNER ROTOR RESPONSES WITH LOAD

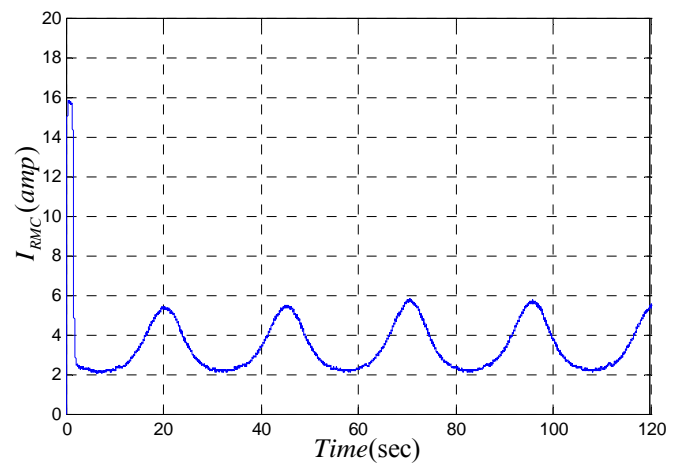

FIGURE XIV. CURRENTS PROFILE OF THE RMC WITH LOAD

\section{CONCLUSION}

The mathematical model of the generator with the RMC can be estimated by second order model and compared to the experimental data by parameter estimation which can be used to design PI controller. The results of an experiment demonstrated that the proposed speed control with PI controller is efficient to control the inner rotor speed with 600$800 \mathrm{rpm}$ range and its outer rotor variable speed with 2000$3000 \mathrm{rpm}$ range and of $0-1$ watt load.

\section{ACKNOWLEDGMENT}

The authors would like to express great thanks to Suranaree University of Technology (SUT) and Synchrotron Light Research Institute (Public Organization) for the research grant.

\section{REFERENCES}

[1] Andrew Miller, Edward Muljadi and Donold S. Zinger., "A Variable Speed Wind Turbine Power Control," IEEE Transaction on Energy Conversion, vol.12(2), pp.181-186.,June 1997.

[2] Y. D. Yao, D. R. Huang, C. C. Hsieh, D. Y. Chiang, and S. J. Wang, "Simulation Study of the Magnetic Coupling between Radial Magnetic Gears," IEEE Transaction. Magnetic, vol.33(2), pp. 2203-2206, March 1997. 
[3] R. G. Montague, C. M. Bingham, and K. Atallah, "Magnetic Gear Dynamics for Servo Control," in Proceeding of the $201015^{\text {th }}$ IEEE MELECON, pp. 1192-1197, 2010.

[4] K. Atallah, J. Wang, S. D. Calverley, and S. Duggan, "Design and Operation of a Magnetic Continuously Variable Transmission," IEEE Transaction on Industry Application ,vol. 48(4), pp. 1288-1295, August 2012.

[5] Y. H. Shin, S. C. Kim, and M. S. Kim, "Use of Electromatic Clutch Water Pump in Vehicle Engine Cooling System to Reduce Fuel Consumption," Energy, vol.54, pp.624-631, August 2013.

[6] M. K. Chakravarthi, K. Gupta, J. Malik, and N. Venkatesan, "Linearized PI Controller for Real-Time Delay Dominat Second Order Nonlinear System," in Proceeding of the 2015 ICCICCT, pp. 236-240, 2015.

[7] C. K. Yoo, H. J. Kwak, and I. B. Lee, "Direct Identification Method of Second Order Plus Time Delay Model Parameters," Chemical Engineering Research and Design, vol.79(7), pp. 754-764, October 2001

[8] T.Pongamg, V.Khomphis and J.Srisertpol, "System Modeling and Temperature Control of Reheating Furnace Walking Hearth Type in Setting Up Process" Journal of Mechanical Science and Technology, vol.28(8), pp.3377-3385, 2014. 